\section{Standardize the diet for zebrafish model}

The standardization of diets for laboratory rodents in the 1970 s minimized the contribution of unintended nutritional effects to experimental outcomes and made comparison between experiments more reliable (Nature 491, 31-33; 2012). Despite success as a model species, zebrafish (Danio rerio) are still fed assorted commercially available diets of largely unknown nutrient composition. It is time to develop a standard formula diet for zebrafish in the laboratory, applying the extensive knowledge of fish nutrition from aquaculture.

We analysed the iron content of four commercial zebrafish diets and found that they contained 0.6-4.6 grams of iron per kilogram $\left(\mathrm{g} \mathrm{kg}^{-1}\right)$ of dry feed. Because fish have a maximum iron requirement of $0.2 \mathrm{~g} \mathrm{~kg}^{-1}$ dry feed, these higher concentrations could be toxic. In salmon, for example, differences in dietary iron affect the cytochrome P450 detoxification system (A. Goksøyr et al. Can. J. Fish. Aquat. Sci. 51, 315-320; 1994). One zebrafish diet was also deficient in vitamin $\mathrm{C}-\mathrm{a}$ combination that would alter cellular redox status and could influence study parameters such as disease progression.

Failure to control for such variables compromises the validity of outcomes from zebrafish receiving different nutrition in an otherwise identical experiment.

Sam Penglase National Institute of Nutrition and Seafood Research (NIFES), Bergen; and University of Bergen, Norway. spe@nifes.no Mari Moren, Kristin Hamre NIFES, Bergen, Norway.

\section{Clean stoves already in use in rural India}

The health and pollution problems caused by primitive heating stoves (Nature 490, 343;
2012) are already being addressed in one rural Indian community.

In the state of Arunachal

Pradesh in the eastern Himalayas

- a biodiversity hot spot

(N. Myers et al. Nature 403, 853-858; 2000) - most people use biomass fuel as their primary source of energy. It is burnt in a safe, energy-efficient and smokefree stove called a chulha.

This portable iron stove is enclosed, equipped with a heat-intensity control, an ash-collection tray and an exhaust pipe. It costs just 1,500-3,000 rupees (US\$28-56), and has a thermal efficiency of $60 \%$, compared with $6-8 \%$ for traditional stoves. This translates into a significant saving of around 300 kilograms of wood fuel (biomass) equivalent per year (J. S. Rawat et al. Curr. Sci. 98, 1554; 2010).

These improvements have proved to be a boon for rural women living in poor socio-economic conditions. Sudhir Kumar Jaypee University of Information Technology, Waknaghat, Himachal Pradesh, India.

sudhir.syal@juit.ac.in

\section{Union improves postdocs' rights}

As president of the union UAW Local 5810, which represents more than 6,000 postdocs at the University of California, I recognize efforts by the US National Postdoctoral Association to improve our working conditions (Nature 489, 461-463; 2012). But our union's experience has shown that recommending changes is not enough: organizations need formal negotiating power to make them effective.

UAW Local 5810 has bargained collectively for measurable improvements for postdocs. These include a contract with a minimum salary scale that matches that of the US National Institutes of Health's National Research
Service Award, a stable and comprehensive benefits plan, greater job security and the right to career-development resources.

The parental-leave policy negotiated by the union should help to address the underrepresentation of women in science and engineering and retain top talent. Also, our advocacy for an increase in federal research funding has earned the support of thousands of postdocs and more than 20 members of Congress from California.

These hard-won successes should be an encouragement to postdocs everywhere to organize union support (Nature 467, 739-741; 2010).

Neal Sweeney University of California, Santa Cruz, California, USA.

president@uaw5810.org

\section{Biomedical network in South America}

The organization MERCOSUR - dubbed the Common Market of the South - promotes free trade and movement of goods, people and currency within a trade bloc of five countries in South America. The organization has now funded a large biomedical network spanning research institutes in Argentina, Brazil, Paraguay and Uruguay. We hope that this unprecedented initiative will encourage other regional scientific endeavours in South America.

The idea of the network is to help each other develop innovative biomedical projects that have potential for translational medicine.

The network will encourage contributions from young investigators.

It aims to study the biological and epidemiological aspects of diseases that have social and economic impact; to create biotechnology platforms for clinical developments; and to build up human resources and

technology to a high standard.

In recognition of the importance of investment in science and technology on the development and welfare of communities, MERCOSUR will provide US\$7 million, with a further $\$ 3$ million coming from national funding. The MERCOSUR funding will come from its FOCEM budget, better known for supporting local construction projects such as roads or hospitals.

Eduardo Arzt ${ }^{\star}$ Biomedicine Research Institute of Buenos Aires, CONICET-Partner Institute of the Max Planck Society, Buenos Aires, Argentina. earzt@fbmc.fcen.uba.ar ${ }^{*}$ On behalf of 4 co-authors (see go.nature.com/s6ud4k for a full list).

\title{
Environmental stress seen since antiquity
}

I agree that biologists and sociologists need to get their acts together to determine the effects of environmental stress on our behaviour (Nature 490, 143; 2012). You mention Francis Galton as the first to define its terms, but this discussion was going on long before his and Charles Darwin's time.

'Environmental determinism' has been an issue for at least 2,500 years. For example, it was discussed by Hippocrates and Strabo, by the Muslim historian Ibn Khaldun in his fourteenthcentury book Muqaddimah and by the French philosopher Montesquieu in his political treatise The Spirit of the Laws in 1748.

Frank Vereecken La Hulpe, Belgium.

vereecken@yahoo.com

CONTRIBUTIONS

Correspondence may be sent to correspondence@ nature.com after consulting the guidelines at http:// go.nature.com/cmchno. 